\title{
O NÃO DESEJO PELA PARENTALIDADE ENTRE INDIVÍDUOS HOMOSSEXUAIS
}

\section{Gabriel Bloedow da Silveira1; Cristina Saling Kruel²}

\section{RESUMO}

O presente estudo objetiva descrever os fatores envolvidos no não desejo de indivíduos homossexuais pelo exercício da parentalidade, apontando o estado de desenvolvimento científico nessa temática. Para tanto, foi desenvolvida uma pesquisa de cunho qualitativo, através de uma revisão narrativa da literatura. Os resultados indicam que o não desejo pela parentalidade entre homossexuais se dá em torno de variáveis bastante específicas a esta população. Nesse sentido, a antecipação elevada de estigmas e violências e o escasso espaço de pertencimento e suporte social foram identificados como os principais fatores. Além disso, identificaram-se indícios que sugerem uma experiência diferenciada entre as populações gay e lésbica, em função de estigmas de gênero que podem pressionar as mulheres e distanciar os homens do exercício parental. Conclui-se que a literatura apresenta importantes estudos que evidenciam antecipações negativas e pressões de gênero como os principais fatores influenciadores de um não desejo pela parentalidade entre indivíduos homossexuais.

Palavras-chave: Homoparentalidade; Minorias Sexuais; Psicologia.

Eixo Temático: Atenção Integral e Promoção à Saúde.

\footnotetext{
1 Universidade Franciscana. gabrielbloedowds@gmail.com

2 Universidade Franciscana. cristinaskruel@gmail.com
} 


\section{INTRODUÇÃO}

A criação de filhos por casais do mesmo sexo, denominada parentalidade homoafetiva (ou homoparentalidade), é um fenômeno recente que ainda se encontra em um profundo processo de legitimação social. Durante séculos da história moderna, rígidas estruturas heteronormativas barraram a parentalidade homoafetiva de qualquer lugar de pertencimento no meio social. No final do século XIX, transformações sociais importantes deram início a um processo de individualização ainda em curso nos dias de hoje, que começou a proporcionar espaço social para novos modos de posicionamento dos sujeitos na sociedade, entre eles as vivências homossexuais. Esse processo foi ampliado de maneira importante na década de 1960, quando movimentações sociais históricas atreladas à revolução sexual enfraqueceram estruturas sociais anteriormente absolutas. A partir do século XXI, modernas tecnologias de reprodução medicamente assistida, assim como o avanço de conquistas pelos direitos das minorias sexuais, ampliam as possibilidades de constituição de uma família. Além disso, o avanço da ciência moderna não confirma preceitos tradicionais quanto a formação de uma família, pelo contrário, expande este conceito à medida que vem confirmando a não obrigatoriedade de um casal heteroafetivo, mas sim a performance de papéis parentais independentes de gênero para a criação de filhos (GATO, 2014).

No entanto, a literatura científica sugere menor tendência para o exercício da parentalidade entre pessoas homossexuais, em comparação a indivíduos heterossexuais (LEAL, GATO \& TASKER, 2018; RISKIND \& TORNELLO, 2017; GATES, 2007). Ainda, entre os homossexuais, existem indícios de tendências diferenciadas pelo exercício parental entre mulheres lésbicas e homens gays. Entender os fatores envolvidos no não desejo de homossexuais pela parentalidade pode ser uma importante ferramenta para uma adequada compreensão da realidade vigente, formando as bases para possibilidades de intervenção nesse sentido. Portanto, o objetivo do presente trabalho é descrever os fatores envolvidos no não desejo de indivíduos homossexuais pelo exercício da parentalidade, apontando o estado de desenvolvimento científico nessa temática. 


\section{METODOLOGIA}

O presente estudo é de natureza qualitativa, desenvolvido por meio de uma revisão narrativa da literatura. Foram consultadas publicações que dizem respeito ao tema da pesquisa, nas plataformas Scientific Electronic Library Online (SciELO), Google Scholar e Public MEDLINE (PubMed), nos idiomas inglês e português.

A metodologia qualitativa caracteriza-se pela importância da interpretação, por parte do pesquisador, do fenômeno estudado, tecendo argumentações e considerações acerca do tema (PEREIRA et al, 2018). A revisão narrativa, por sua vez, é uma forma não sistemática de revisão literária, adequada para o desenvolvimento de publicações amplas que se proponham a descrever o "estado da arte" de determinado tema (ROTHER, 2007). Considerando o objetivo do presente trabalho, optou-se por essa configuração metodológica por entender que a mesma atende de maneira efetiva a uma descrição de realidade e apontamento do estado de desenvolvimento atual do conhecimento científico.

\section{RESULTADOS E DISCUSSÕES}

Diferentes estudos quantitativos apontam para uma menor intenção para a parentalidade entre indivíduos homossexuais, quando em comparação a heterossexuais (LEAL, GATO \& TASKER, 2018; BAIOCCO \& LAGHI, 2013; RISKIND \& PATTERSON, 2010). Tal realidade contrasta com recentes avanços jurídicos e científicos que vêm facilitando o acesso dessa população ao exercício parental (GATO \& FONTAINE, 2017). Esse cenário sugere que a menor intenção de parentalidade entre os homossexuais possa estar principalmente relacionada a outros fatores para além de dificultores jurídicos e biológicos. Nesse sentido, a literatura apresenta indicadores que circunscrevem essa menor tendência ao exercício parental muito mais a dificuldades sociais e culturais que interferem no desejo pessoal pela criação de filhos (LEAL, GATO \& TASKER, 2018; ALLEN \& HENDERSON, 2016; TORNELLO, FARR \& PATTERSON, 2011).

À vista disso, entende-se que indivíduos homossexuais antecipam um maior estigma social associado à parentalidade (LEAL, GATO \& TASKER, 2018), que pode estar conectado a um contexto social predominantemente heteronormativo. Esse fator 
pode se relacionar à vivência do chamado "estresse de minoria" (MEYER, 2003); conceito que se refere a um estresse específico vivido pelas minorias sociais e que aponta, para a homossexualidade, a imposição de um estigma social e a internalização da homonegatividade como alguns dos principais estressores (LAWRENZ \& HABIGZANG, 2019). No entanto, publicações também indicam a possibilidade de que indivíduos homossexuais, por já estarem afastados das performances sociais tradicionais, sintam menor pressão para o exercício parental (LEAL, GATO \& TASKER, 2018; BAIOCCO \& LAGHI, 2013).

Além disso, a literatura consultada observa que há pouco espaço de pertencimento social para indivíduos homossexuais com filhos. Mesmo dentro da própria comunidade LGBT+, observam-se poucas pautas organizadas em torno da parentalidade, estando a maior parte das atividades centradas em indivíduos solteiros e sem filhos (GATO, 2014). Nesse sentido, alguns estudos chegam a relatar que a transição para a parentalidade pode ocasionar um afastamento da comunidade LGBT+ entre homossexuais (ARMESTO \& SHAPIRO, 2011; WELLS, 2011). Tais achados vão ao encontro aos resultados de alguns estudos que percebem pouca antecipação de suporte social entre homossexuais que desejam ter filhos (BAIOCCO \& LAGHI, 2013; LEAL, GATO \& TASKER, 2018).

No que tange o recorte de gênero, enquanto alguns estudos não identificam diferenças com relação a esta faceta (LASIO et al, 2020; COSTA \& BIDELI, 2017), outras publicações evidenciam um menor desejo para a parentalidade entre a população homossexual masculina, quando em comparação com a feminina, e viceversa (RISKIND \& PATTERSON, 2010; RISKIND \& TORNELLO, 2017). Nesse sentido, Baiocco \& Laghi (2013) sugerem que homens gays preveem menor suporte social para o exercício parental do que mulheres lésbicas. Essa realidade pode estar em função de estigmas sociais que posicionam a criação de filhos como uma tarefa exclusiva da feminilidade. Em seu estudo, Gato (2014) aponta para uma convicção social, largamente partilhada, de um suposto instinto materno essencial para a criação de filhos que estaria circunscrito unicamente à população feminina. Na contramão, esse mesmo mecanismo pode estar pressionando mulheres lésbicas para o cumprimento da maternidade como uma tarefa da feminilidade (AMODEO et al, 2018). 
Observa-se, portanto, uma dinâmica de papéis de gênero que é socialmente imposta tanto a mulheres quanto a homens, mas que é vivida em lados opostos por cada grupo e pode estar interferindo na maneira diferenciada com que o desejo pela parentalidade se expressa entre as populações gay e lésbica. Além de uma pressão, é apontado que mulheres lésbicas podem sentir, mesmo inconscientemente, uma possibilidade de elevação social a partir da maternidade (AMODEO et al, 2018). Do outro lado, homens gays, além de não encontrarem na masculinidade tradicional a tarefa da parentalidade, sentir-se-iam deslocados de um lugar de cuidado supostamente feminino e ausentes de um instinto materno de cuidado (GATO, 2014). É evidente que essa dinâmica nem sempre se expressa de maneira consciente e objetiva, mas é possível que esteja presente nos processos de subjetivação atuais, suscitando, além das dificuldades comuns à ambos os gêneros, uma produção de desejo diferenciada para a criação de filhos entre homens e mulheres homossexuais.

\section{CONCLUSÃO}

Atualmente, a vivência da parentalidade por pessoas homossexuais ocorre em função de fatores bastante específicos a esta população, principalmente no que diz respeito ao âmbito social. Tais variáveis influenciam no desejo pela parentalidade na medida em que estão presentes nos processos de subjetivação dos indivíduos, expressando-se na antecipação de estigmas, violências e suporte social diminuído. No presente estudo, essas antecipações foram identificadas como os principais fatores influenciadores de um não desejo pela parentalidade entre indivíduos homossexuais.

Observou-se, ainda, um importante indicativo de diferença na produção de desejo para a criação de filhos entre as populações homossexuais masculina e feminina. Essa diferença parece acompanhar estigmas sociais sexistas que circunscrevem a criação de filhos exclusivamente à feminilidade. Esse cenário tende a gerar um ambiente social de pressão para o exercício da parentalidade entre mulheres lésbicas, e desmotivação para a ocupação desse espaço entre homens gays. Nesse sentido, é interessante perceber como, ainda que homens e mulheres homossexuais estejam, de modo geral, afastados das normativas sociais tradicionais, 
UCACÃO, SAÚDE

ETECNOLOGIA

26 A 28 DE OUTUBRO DE 2021

parecem ser atingidos de maneira importante por estigmas relativos à performance de papéis de gênero, especialmente no que diz respeito à parentalidade.

Ainda, é importante salientar que a divergência existente entre estudos recentes com relação à diferença de desejo pela homoparentalidade entre os gêneros masculino e feminino indica a necessidade de um maior desenvolvimento de pesquisas nessa temática, visando a maturação do conhecimento científico. Além disso, uma limitação importante da produção científica atual diz respeito à pouca diversidade de realidades sociais apreendidas pelas coletas de dados, pois a maioria dos estudos disponíveis foram aplicados em populações europeias e norteamericanas, notadamente de Portugal, Itália, Reino Unido e Estados Unidos. Finalmente, recomenda-se que pesquisas futuras atentem para realidade social de países subdesenvolvidos e emergentes, assim como atentem-se para uma coleta de dados entre populações além das classes média e alta.

\section{AGRADECIMENTOS}

O presente trabalho contou com financiamento do programa PROBIC da Universidade Franciscana.

\section{REFERÊNCIAS}

ALLEN, K. R.; HENDERSON, A.C. Family Theories: Foundations and Applications. Chichester, UK: John Wiley \& Sons. 2016

AMODEO, A.L. et al. Parenting Desire and Minority Stress in Lesbians and Gay Men: A Mediation Framework. International Journal of Environmental Research and Public Health, v. 15, n. 10, 2018.

ARMESTO, J.C.; SHAPIRO, E.R. Adoptive gay fathers: Transformations of the masculine homosexual self. Journal of GLBT Family Studies, v. 7, n. 1-2; pp 72-92. 2011. 
BAIOCCO, R.; LAGHI, F. Sexual Identity and the Desire and Intention to Become Parents. Journal of Family Studies, v. 19; pp 90-98. 2013.

COSTA, P. A.; BIDELL, M. Modern families: Parenting desire, intention, and experience among Portuguese lesbian, gay, and bisexual individuals. Journal of Family Issues, v. 38, n. 4; pp 500-521. 2017.

GATES, G. J.; BADGETT, M. L.; MACOMBER, J. E.; CHAMBERS, K. Adoption and Foster Care by Gay and Lesbian Parents in the United States. Washington, DC: The Urban Institute. 2007.

GATO, J. Homoparentalidades: perspectivas psicológicas. Coimbra: Almedina. 2014.

GATO, J.; FONTAINE, A. M. Predicting Attitudes Toward Lesbian and Gay Parent Families Among Portuguese Students from Helping Professions. International Journal of Sexual Health, v. 29, n. 2; pp 187-201. 2017.

LASIO, D.; LAMPIS, J.; SPIGA, R.; SERRI, F. Lesbian and Gay Individual Parenting Desires in Heteronormative Contexts. Europe's Journal of Psychology, v. 16, n. 2, pp 210-228. 2020.

LAWRENZ, P.; HABIGZANG, L.F. Minority Stress, Parenting Styles, and Mental Health in Brazilian Homosexual Men. Journal of Homosexuality, v. 67, n. 5, p. 658673,2020

LEAL, Daniela; GATO, Jorge; TASKER, Fiona. Prospective parenting: sexual identity and intercultural trajectories. Culture, Health \& Sexuality, v. 21, n. 7, p. 757-773, 2019. 
MEYER, I. H. Prejudice, social stress, and mental health in lesbian, gay, and bisexual populations: Conceptual issues and research evidence. Psychological Bulletin, v. 129, n. 5; pp 674-697. 2003

PEREIRA, A. S., SHITSUKA, D. M., PARREIRA, F. J., \& SHITSUKA, R. Metodologia da pesquisa científica. Santa Maria: Ed. UAB/NTE/UFSM. 2018. Disponível em: https://repositorio.ufsm.br/bitstream/handle/1/15824/Lic_Computacao_MetodologiaPesquisa-Cientifica.pdf?sequence=1.

RISKIND, R. G.; TORNELLO, S. L. Sexual Identity and Future Parenthood in a 20112013 Nationally Representative United States Sample. Journal of Family Psychology, v. 31, n. 6; pp 792-798. 2017.

RISKIND, R.; PATTERSON, J. Parenting Intention and Desire among Childless Lesbian, Gay and Heterosexual Individuals. Journal of Family Psychology, v. 24; pp 78-812010.

ROTHER, E. T. Revisão sistemática $X$ revisão narrativa. Acta Paulista de Enfermagem, v. 20, n. 2. 2007.

TORNELLO, S. L.; FARR, R. H.; PATTERSON, C. J.). Predictors of parenting stress among gay adoptive fathers in the United States. Journal of Family Psychology, v. 25, n. 4; pp 591-600. 2011.

WELLS, G. Making room for daddies: Male couples creating families through adoption. Journal of GLBT Family Studies. v. 7, n 1-2, pp 155-181. 2011. 